\title{
The Role of Opinion Leaders in Influencing Consumer Behaviors with a Focus on Market Mavens: A Meta-analysis
}

\author{
By Young-Sung Kwon* \\ Hae Ryong Song ${ }^{\dagger}$
}

One of the areas in which the impacts of media messages have been tested is in the goods and services market. A number of studies have shown that the behaviors of consumers in the market are significantly influenced by market mavens, the expert consumers who have market information regarding different products, especially new products in the market. Different scholars have argued that the market mavens have had a significant influence on the behaviors of consumers through mouth to mouth communication. This research study sought to investigate how market mavens play the role of opinion leaders. In essence, the study wanted to prove the veracity of the two step flow theory of mass communication, the study utilized a meta-analysis technique in achieving its goals. The findings included the fact that opinion leaders actually played a major role in influencing the decisions of passive audiences. A number of studies have been done to determine how market mavens obtain product information from the media and pass it to other passive consumers according to the way they interpret the information. In this regard, there are not adequate meta-analyses that have been done to compare, contrast and combine the results of the different studies. This is the reason this study was done.

\section{Introduction}

\section{Background of the Study}

According to Walsh and Elsner (2012), one of the areas in which the impacts of media messages have been tested is in the goods and services markets. A number of studies that have been done by the two scholar have shown that the behaviors of consumers in the market are significantly influenced by market mavens, the expert consumers who have market information regarding different products, especially new products in the market. Armelini and Villanueva (2010) have posited that the market mavens have had a significant influence on the behaviors of consumers through mouth to mouth communication (Walsh and Elsner, 2012).

${ }^{*} \mathrm{PhD}$ Student, Department of Journalism and Mass Communication, Sungkyunkwan University, South Korea.

${ }^{\dagger}$ Professor, Department of Journalism and Mass Communication, Sungkyunkwan University, South Korea. 


\section{Statement of the Problem}

Many researchers, such as Yang (2013) and Chelminski and Coulter (2012), have done research studies with a view to determining how market mavens obtain product information from the media and pass it to other passive consumers, mostly in the form of their own interpretations and understandings. Unfortunately, despite the many studies, there are still not adequate metaanalyses that have been done to compare, contrast and combine the results of the different studies with the intention of building a bigger picture of how market mavens influence the behavior of consumers. This is the reason this study was done.

\section{Objectives of the Study}

To conduct a critical literature review to discover what past researchers had done with respect to the way market mavens obtained media messages and passed it to other consumers according to their own interpretations.

To determine how consumers reacted to information passed to them by market mavens

To establish whether or not market mavens passed the information they obtained from the media to consumers in its original form.

\section{Research Questions and Hypotheses}

Are there differences in the findings of previous studies with respect to the influence of mavens in the market?

How do consumers react to information passed to them by market mavens?

Do market mavens pass information to other consumers in their exact original forms?

$\mathrm{H}_{0}$ : There is no relationship between market mavens' opinions and the choice of other consumers and opinion seekers.

$\mathrm{H}_{\mathrm{a}}$ : There is a relationship between market mavens' opinions and the choice of other consumers and other opinion seekers.

\section{Purpose of the Study}

The main purpose of the study was to compare, contrast and combine the results of various studies that had been done on how market mavens influence the behavior of consumers and other opinion seekers with respect to product purchases.

\section{Justification of the Study}

There were not adequate meta-analyses that had been done to combine the results of different studies that had been done with respect to how consumers and other opinion seekers were influenced by how market mavens interpreted media information on different products and passed it to them. This study therefore sought to undertake the meta-analysis in order to generate relevant and up-to-date information on the link between market mavens and consumers. 


\section{Literature Review}

Dalrymple, Shaw and Brossard (2013) have done a substantial number of empirical studies in which they have established that opinion leaders have statistically significant influences on the individual behaviors of other people. Dalrymple, Shaw and Brossard (2013) have provided a generalized information, and they failed to give the demographics of the opinion leaders and the level of their influences in terms of age, gender and other factors. Besides, the above researchers have failed to indicate whether the study was conducted worldwide or within a specific location.

Williams and Duvel (2005) investigated the nature, the occurrences and the factors that influenced opinion leaders specifically in Lesotho; they found out that opinion leadership was influenced by age, gender and marital status. Despite the findings, Williams and Duvel (2005) concluded that opinion leaders of Lesotho had a relatively lower level of education, the finding of which has been discounted by Sarathy and Patro (2013), who have established that opinion leaders are not only younger and have higher occupational statuses, but are also more educated than the people they seek to influence.

Lee (2010) and Vishwanath (2011) claim that the choices made by individuals are usually shaped by the perceptions or opinions of others; the claim suggests that other factors such as age, gender, marital status and socioeconomic class do not matter much. But, as noted with the findings of Sarathy and Patro (2013), most opinion leaders are young, have post-high school education and occupy higher occupational and social statuses.

Chakrabarti (2013) and Gielens (2012) affirm that opinion leaders play a major role in influencing the way opinion seekers behave or act with respect to making purchases in the services and goods markets. Conversely, even though the affirmation is true, it is so only to a certain extent. There are other factors, which actually play a major role in determining the behavior of consumers toward making purchases. For instance, Diaz and Maria (2013) contend that prices play a critical role in influencing consumer behaviors; if consumers are presented with relatively high prices, they are more likely to shift to the purchase of alternative products. This implies that it does not matter what the recommendations of opinion leaders are, consumers will consider the price they are required to pay and the value of what they purchase.

Besides, Diaz and Maria (2013) have also established that when consumers are initially presented with higher prices, and later with lower ones, they are likely to consider making purchases at the new lower prices. This means that sellers can manipulate the cognition of buyers by playing around with prices to influence them into making purchases. The implication of this is that opinion leaders do not play a major role in influencing consumption behavior.

Moreover, different scholars, such as Bruno and Hustad (2013), have acknowledged that opinion leaders act as the middle people between the public and the media. The acknowledgement implies that the opinion leaders receive messages from the media, interpret and pass them to other members of the 
community according to their own understandings. Klingemann and Rommele (2002) add to the discourse by arguing that opinion leaders interpret the information they obtain from the mass media according to their own cultural and social contexts. Klingemann and Rommele (2002) therefore rightly concludes that in such a context, the mass media has much less influence in shaping the perception of the public; the opinion leaders who interpret media messages do.

Denesi (2013) and Hustad (2013) reveal that the opinion leaders are not necessarily having formal positions within the society, and they do not wield power in the formal contexts. However, Bilinska and Sztangret (2013) have identified the opinion leaders as individuals who act as intermediaries to inform others about what the salient issues are as determined by the media; according to the foregoing scholars, in the process of influencing the behaviors of opinion seekers, the opinion leaders also pass their personal opinions, which are often believed. This argument tends to agree with that of Klingemann and Rommele (2002).

Even though the influence of opinion leaders cannot be ignored, Bilinska and Sztangret (2013) further submit that a good number of individuals actually get information or messages directly from the media. In this respect, the implication is that opinion leaders really do not play much role in influencing the perception of the members of a community. This tends to contradict the two-step flow theory; because any other individual person is able to get messages directly from the mass media the same way opinion leaders do.

\section{Theoretical Underpinning}

This study was based on the two step flow theory of communication. Williams (2012) explains that according to the two-step flow theory, most individuals form their opinions based on the influence of opinion leaders, who are in turn influenced by the messages from the mass media. In this respect, Laughey (2007) argues that information flows from the mass media to opinion leaders and in turn flows from the opinion leaders to a wider population. For purposes of this study, the theory was used to explain how product information flowed from the mass media to opinion leaders, and ultimately to a wider community. The theory was chosen because it captures the idea of some people being able to get information from different sources, interpret and pass it to opinion seekers.

The theory has been criticized on various grounds. For instance, Littlejohn and Foss (2008) have advised that the theory should be applied to mass communication with a lot of caution, because it is only limited to the media environment, with the exclusion of the television. The researchers have argued that the initial mass media messages flow directly to individuals on the whole and is actually not transmitted by opinion leaders, especially in the case of television, which is increasingly becoming accessible to many people who are not opinion leader. Littlejohn and Foss (2008) have also argued that research studies that were done after the theory was established in the 1940s have 
shown that there are more than just two steps in the communication process; there are multistep flow of influence.

Baran (2007) contends that the two step theory of communication does not sufficiently describe the flow of learning. According to Baran (2007), almost half of the respondents he surveyed reported to have obtained their learning experience directly from the media. This claim negates the proposition by the two flow theory of communication that most audiences obtain information from opinion holders who in turn get the information from the mass media.

\section{Research Gap}

The different studies that have been done have produced a lot of insightful information about the influence of opinion leaders on other members of the society. However, there has not been even a single one of them in which a meta-analysis has been done to combine the results of different studies to get a bigger picture of the influence of market mavens on choice behavior of consumers in the market. This is where this study came in.

\section{Research Methodology}

This study utilized quantitative approaches in achieving its objectives. Quantitative approaches were preferred due to their objectivity and relevance to the process of a meta-analysis. Besides, Piggot (2012) and Doyle (2010) advise that quantitative approaches are always the most appropriate in conducting any form of an empirical study. This is because they allow a researcher to obtain statistical data, formulate and test hypotheses, and establish a new theory or prove the existing ones, a claim that is strongly supported by Osbirne (2008).

A total sample of 20 dissertations was selected and their results combined through a meta-analysis process. A meta-analysis is a type of an empirical research in which the results of different studies are statistically combined to obtain a general effect size with respect to a phenomenon studied. The 20 dissertations were selected from among those which were done between 2010 and 2013. This was because they were the most recent studies that had been done. The inclusion criteria included the consideration of the credibility of the authors, the year of study, methodologies used and the statistical approaches employed in every study.

Data was extracted from the dissertation according to the common questions that were addressed by all the dissertations. The analysis process involved the use of statistical approaches such as standard, deviation, effect size and p-values.

\section{Findings and Discussions}

\section{Test of Hypothesis}

The first thing that was done in the analysis of the data obtained from the dissertations was to determine the veracity of the null hypothesis. The 
probability value used was $\mathrm{p}<0.05$. In this case the calculated value came out to be 0.03 , which was less than the significance level of 0.05 . Therefore, the null hypothesis was rejected and the effect of the obtained value was interpreted as being statistically significant. This means that the effect of mavens' opinions on the consumer choices was significant.

\section{Influence of Market Maven's Opinions on Consumer Decisions}

The dissertations that tackled similar research questions were analyzed together. In 8 of the 20 dissertations, researchers sought to determine how youths made their purchase choices of the products in the market. It is important to note that the questions that were put to respondents in each of the 8 dissertations were varied, but they dealt with similar themes. The results of the dissertations were therefore combined in terms of themes and then analyzed quantitatively. Hence, the results for all the 8 dissertations showed that a mean of $38 \%(\mathrm{SD}=2.4 \%)$ indicated that they made purchases as a result of peer influence. In the same dissertations, an average mean of $20 \%(\mathrm{SD}=3 \%)$ had been guided by their guardians' opinions. Surprisingly, an average mean of $75 \%(\mathrm{SD}=3.8 \%$ ) of the respondents indicated that they followed the opinion of others in making purchase choices despite having access to information directly from the mass media.

The average of $75 \%$ represented the results of the responses as provided by the respondents who had indicated that they depended on various reviews by other people different from their relatives and close friends to make their purchase decisions. Figure 1 summarizes the foregoing results.

\section{Figure 1. Factors that Influence the Purchase Behavior of Youths}

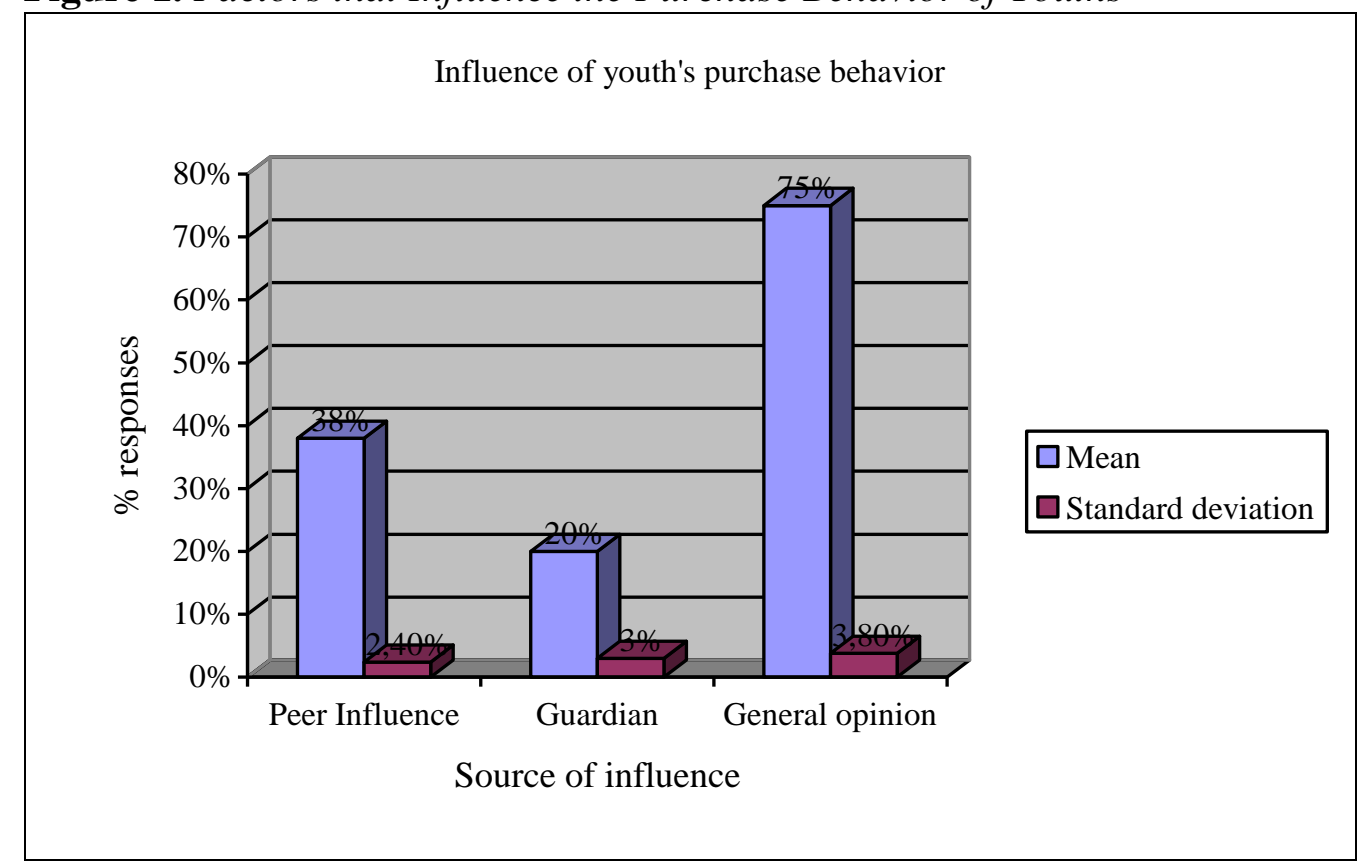

In 10 other studies, researchers surveyed a total of 14000 consumers. The researchers found out that an average of $66 \%(\mathrm{SD}=0.9 \%)$ of the consumers 
indicated that they were influenced to use new product brands by other individuals who had more information on the product brands; besides, an average of $40 \%(\mathrm{SD}=5 \%)$ indicated that they had formulated their personal opinions on new product brands after getting promotional messages from the media; however, according to the average result of the studies, they changed their minds after they were persuaded by their "trusted" people, who had used the new brands. Besides, the study found out that an average of $45 \%$ $(\mathrm{SD}=2.5 \%)$ of respondents had indicated that they intended to purchase specific brand of products after the media highlighted their good qualities but ended up buying different products that they felt most people preferred at the time; therefore, to them, they were weighed between product information they got from the media and the brand that most people preferred at the time. Ultimately, they thought that what people purchased the most was the best brand, so they ended up changing their minds on what to purchase. In the same group of respondents, an average of $39 \%$ ( $\mathrm{SD}=7.2 \%$ ) were found to have made brand purchases based on the information they got directly from the media. Figure 2 provides a summary of these results.

Figure 2. How Individual Purchase Behaviors were Influenced

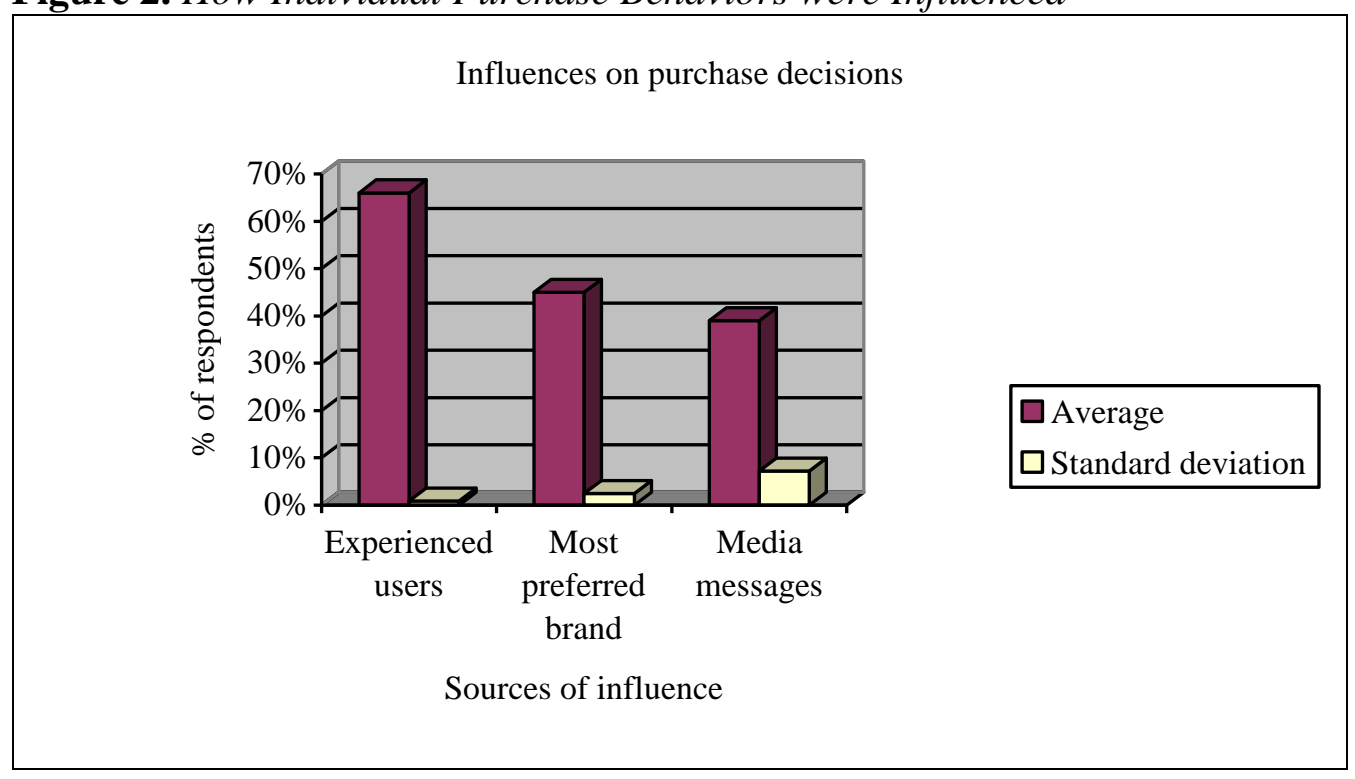

Of the 10 dissertations, on 4 asked those who had made purchases based on media messages whether or not they had other alternative sources information about the brands they purchased. In that case, an average of 55.8\% $(\mathrm{SD}=4.6 \%)$ indicated that they had access to other sources of information, while $21.3 \%$ ( $\mathrm{SD}=3 \%$ ) indicated that they did not have access to any other media. The rest of the results of the dissertations were about the respondents who had indicated that they were either neutral or those who did not respond to the questions; these were grouped as "others." Figure 3 gives the summarized form of the above results. 
Figure 3. Responses on the Access to Alternative Information other than Media Messages

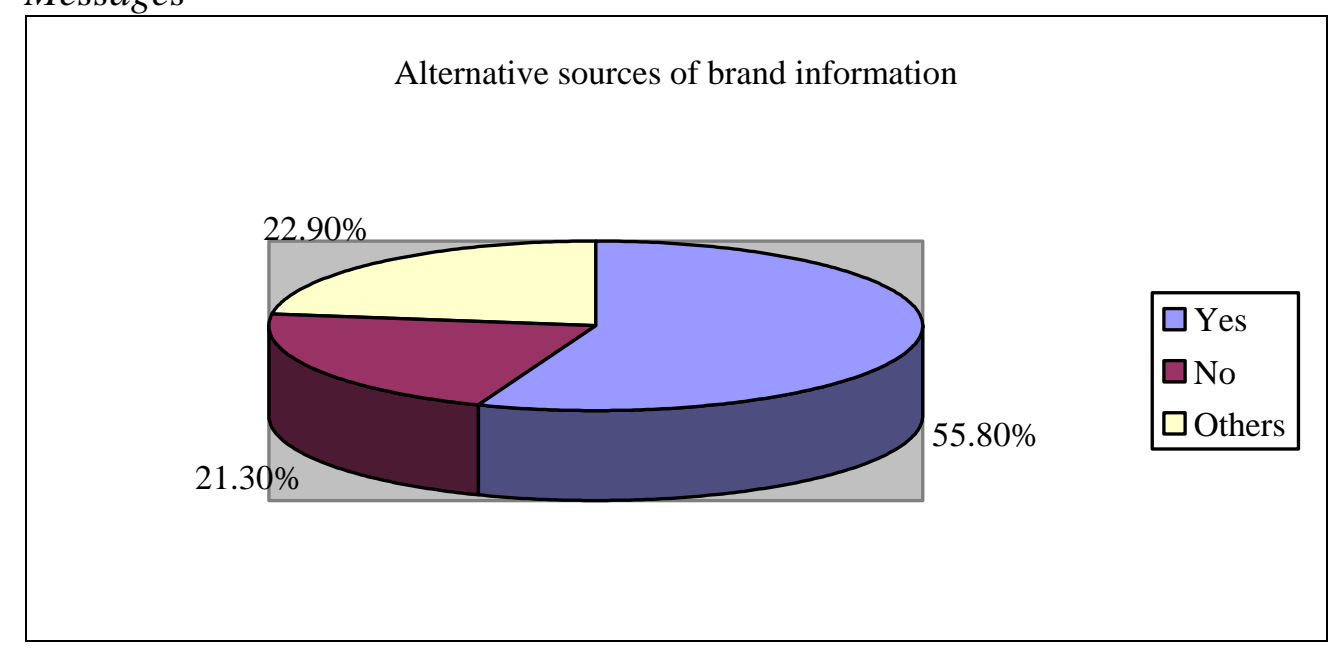

Five of the dissertations sought to find out the negative impact of negative review of products on purchase decisions made by consumers. The studies that were done were repeats of previous studies. The researchers used experimental methods to determine the effect of positive and negative product reviews had on consumer decisions. For each study, the respondents were divided into two groups: treatment and control groups. Both groups were first exposed to a similar positive message about a particular product. After the exposure, the members were asked whether they would consider buying the product. Surprisingly, an average of $81 \%(\mathrm{SD}=7)$ indicated that they would consider buying the product. The researchers in each study then later separated the two groups and subjected one of them to a negative review of the product. When the same question was repeated for each group, the researchers realized a substantial change between the responses from the treatment and the control groups. A meta-analysis of the research findings showed that an average of $89 \%(\mathrm{SD}=2.1)$ of the members in the treatment groups stated that they would not consider buying the product as compared to an average of $77 \%(\mathrm{SD}=2.5)$ of respondents in the control groups who indicated that they would still consider buying the product. At the $95 \%$ confidence level, with a confidence interval (CI) of between 4.3 and 6.1, the Cohen's effect size (d) was found to be 5.2\%. This, according to Cohen, can be considered as a medium effect size; it means that the difference that was observed in the average findings for the two groups was significant and pointed to the fact that the original mass media message can be modified and used to persuade other audiences.

\section{Discussions}

This research study has established that despite the fact that consumers are able to get product information directly from the mass media, they still depend on and, in fact, can be influenced by opinion leaders who have relatively more 
knowledge and information about different products in the market. This was especially observed among the youths. In this regard, the study proved that a significant number of people still depended on the opinions of opinion leaders. This directly corroborates the arguments of researchers who had established the important role of opinion leaders in influencing the decision making processes of opinion seekers.

The study also found out that the youths' decisions to buy specific products in the market were subject to influences from their peers and guardians. In such a scenario, the peers and guardians may add their personal biases when advising others to buy certain products and not others. During the literature review process, this finding was found to be common among a number of other scholars. The consequence of this is that the original message from the mass media may be distorted before it reaches the intended opinion seekers.

The role of mavens with respect to influencing purchase decisions of other consumers was demonstrated by the experiments which showed that some individuals, who had indicated that they would buy a product based on its positive review, changed their minds after they were presented with a negative review. Previous experimental studies had also proved the same. These particular findings further confirmed the truth of the claims of the two step flow communication theory. The implication is that if consumers are not using mass media information to make their purchase decisions, then they are likely to make such decisions based on distorted information, especially where such consumers rely on the opinion on market mavens.

Therefore, it can be concluded that the two step flow model of communication applies to the cases of market mavens and the way they are able to influence the purchase decisions of other consumers. Moreover, the findings of the study were found to be in agreement with the arguments of various authors who were identified during the literature review process. However, the findings contradicted other researchers who had shown that mavens and other opinion leaders did not play a significant role in influencing consumer purchase decisions because such consumers had direct access to product information from the mass media.

It is also important to note that the results of some of the studies had indicated that some respondents actually made their purchase decision purely based on media messages. Therefore, this finding tended to agree with the critics of the two step flow theory of communication. However, it is worth pointing out that the number respondents who revealed to have made their decisions based on media messages were significantly less.

\section{Conclusion and Recommendations}

\section{Conclusion}

The conclusion is that the study was able to meet its objectives; the results of the meta-analysis process proved that indeed there is a relationship between 
market mavens and consumer decision making processes. Importantly, the study was able to prove the two step flow theory. All the results of the dissertations showed that despite direct information from the mass media, consumers still made their purchase decisions based on the opinions of those who were very knowledgeable about the products they wanted to buy.

With respect to the research questions, the study found out that there were not much difference in the results of the 20 dissertations that were metaanalyzed. Besides, the study established that consumers are often likely to consider the opinion of market mavens with respect to making purchase decisions. Lastly, the study established that market mavens may sometimes not pass product information to consumers in exact forms in which they obtain it from the mass media; they may manipulate the interpretations of the mass media messages to achieve their own interests.

\section{Recommendations}

Based on the nature and findings of this study, there are a number of recommendations to make. First, it is important that future studies should utilize primary data in investigating the influence of market mavens on the purchase decisions of other consumers. Besides, future meta-analyses should have more samples to ensure the rigor of the study outcomes. This is because the 20 dissertations that were used in the study were too few to produce meaningful results that could be generalized to a specific population. Lastly, future researchers should use the findings of this study as the foundation of their studies. This will enable them to build on the achievements of this research. In addition, future meta-analysis studies should use the findings of this research study as the foundation for further investigation on a similar topic.

Most studies that were included in this meta-analysis did not considered possible role of gender in the context of opinion leadership. Therefore, it is recommended that future studies on a similar problem should narrow their focus and examine the possible influence of gender on the final results. This will help in determining whether or not male and female audiences are influenced differently by opinion leaders or direct messages from the media.

The last recommendation is that future studies should focus on a specific industry or product line. In relation to this, this study generally focused on the goods and service market, a situation that might have had some unforeseen negative impact on the final results.

\section{Acknowledgments}

This study was supported by grant of the Brain Korea 21 PLUS Program. 


\section{References}

Armelini, G., and Villanueva, J. (2010). Marketing Expenditures and Word-of-mouth Communication: Complements or Substitutes? Hanover, MA: Now Publishers Inc.

Baran, S. (2007). Introduction to Mass Communication: Media Literacy and Culture. Berkshire, England: McGraw-Hill.

Bilinska, K., and Sztangret, I. (2013). Influence of Knowledge Sharing Between Intermediaries and IT Leaders on Developing Offers for Customers - Polish Perspective. International Journal of Management Cases, 15(4), 205-233.

Bruno, A., and Hustad, P. (2013). Product Class Investigation of Innovators and Opinion Leaders. Journal of Business Research, 3(5), 223-238.

Chakrabarti, S. (2013). The Influence of Opinion Leadership and Associated Measures among Owners of High End Smartphone Products in India. Journal of Marketing \& Communication, 8(4), 4-12.

Chelminski, P., and Coulter, R. (2012). Examining Polish Market Mavens and Their Attitudes toward Advertising. Journal of East-West Business, 8(1), 70-79.

Dalrymple, K., and Brossard, D. (2013). Following the Leader: Using Opinion Leaders in Environmental Strategic Communication. Society \& Natural Resources, 26(12), 1438-1453.

Danesi, M. (2013). Encyclopedia of Media and Communication. Toronto, Canada: University of Toronto Press.

Diaz, S., and Maria, I. (2013). Price Assessments by Consumers: Influence of Purchase Context and Price Structure. International Journal of Consumer Studies, 37(1), 13-20. doi: 10.1111/j.1470-6431.2011.01053.x

Doyle, H. (2010). Quantitative Meta-analysis of Trends in Reptile Populations over Time. New York, Routledge.

Gielens, K. (2012). New Products: The Antidote to Private Label Growth? Journal of Marketing Research (JMR), 49(3), 408-423.

Klingemann, H., and Rommele, A. (2002). Public Information Campaigns \& Opinion Research: A Handbook for the Student \& Practitioner. London, UK: SAGE.

Laughey, D. (2007). Key Themes in Media Theory. Berkshire, England: McGraw-Hill International.

Lee, A. (2010). Who Are the Opinion Leaders? The Physicians, Pharmacists, Patients, and Direct-to-Consumer Prescription Drug Advertising. Journal of Health Communication, 15(6), 629-655.

Littlejohn, S., and Foss, K. (2008). Theories of Human Communication. London, UK: Cengage Learning.

Osborne, J. (2008). Best Practices in Quantitative Methods. London, UK: SAGE Publications.

Piggot, T. (2012). Advances in Meta-Analysis. New York, NY: Springer.

Sarathy, P., and Patro, S. (2013). The Role of Opinion Leaders in High-Involvement Purchases: An Empirical Investigation. South Asian Journal of Management, 20(2), 11-53.

Vishwanath, A. (2011). The Effect of the Number of Opinion Seekers and Leaders on Technology Attitudes and Choices. Human Communication Research, 34(7), 295-370.

Walsh, G., and Elsner, R. (2012). Improving Referral Management by Quantifying Market Mavens' Word Of Mouth Value. European Management Journal, 30(1), 74-81. 
Vol. 1, No. $1 \quad$ Kwon: The Role of Opinion Leaders in Influencing Consumer Behaviors...

William, R. F., and Duvel, G. H. (2005). The Nature and Determinants of Opinion Leadership in Lesotho. South African Journal of Agricultural Extension, 34(2), 259-277.

Williams, M. (2012). Game Theory and Technical Communication: Interpreting the Texas Two-Step through Harsanyi Transformation. Journal of Technical Writing \& Communication, 42(4), 373-392.

Yang, H. (2013). Market Mavens in Social Media: Examining Young Chinese Consumers' Viral Marketing Attitude, eWOM Motive, and Behavior. Journal of Asia-Pacific Business, 14(2), 154-178. 